\title{
A clinical audit of the diagnosis of malaria in a rural Ugandan hospital
}

This article was published in the following Dove Press journal:

Clinical Audit

18 June 2015

Number of times this article has been viewed

\author{
Harry Hutchins \\ Clare J Taylor \\ College of Medical and Dental \\ Sciences, University of Birmingham, \\ Birmingham, UK
}

Correspondence: Harry Hutchins

$\mathrm{C} / \mathrm{O}$ Clare J Taylor, Primary Care Clinical Sciences, Learning Centre, University of Birmingham, Edgbaston, West Midlands BI5 2TT, UK

Tel +44 I2I 4I 58629

Email hah9|4@bham.ac.uk
Background: Malaria remains a serious public health issue in Uganda. World Health Organization recommendations have been implemented which aim to reduce the diagnosis of malaria without proper testing: all suspected patients should have a rapid diagnostic test before receiving treatment and certain, more severe cases should undergo blood-smear microscopy. The audit reported here assessed whether Kisiizi Hospital in Uganda's Rukungiri District meets this standard.

Methods: Data were collected over 10 days in May 2014 from a 250-bed private hospital in rural southwestern Uganda. All patients commencing antimalarial treatment were included; new cases were found on daily ward visits and their notes were examined to assess whether diagnostic testing was conducted appropriately. Pharmacy and laboratory records were crosschecked to improve coverage. Proportions of correctly managed patients were then calculated and compared by ward, age group, and sex, and assessed for statistical significance.

Results: Fifty-nine patients were included. Of these, 35 were male and the median age was 18 (interquartile range 4.5-31.0). Seven departments were included in the audit; Outpatients contributed the most patients with 25, while Psychiatry the fewest with one. In total, nine patients were not managed in accordance with guidelines. Three departments correctly tested $100.0 \%$ of patients, with the remainder ranging from $50.0 \%$ to $87.5 \%$. Proportionally more adults were incorrectly managed than children under 18 years, however this was not statistically significant. Men were significantly ( $P=0.0242)$ more likely to be correctly managed than women.

Conclusion: Kisiizi Hospital is performing relatively well in correctly diagnosing patients prior to treatment, compared to hospitals in similar settings. It must strive, however, for improvement. Appropriate staff education may help eliminate the difference between sexes and standardize quality between departments. Improvements in hospital record keeping would facilitate future audits in this and other areas. Re-audit following the implementation of any changes would be desirable.

Keywords: clinical guidelines, rapid diagnostic test, Uganda, World Health Organization recommendations, audit, malaria

\section{Background}

Malaria remains one of the greatest public health problems facing the developing world. Conservative estimates place the annual global death toll at 655,000, of whom $86 \%$ are children under five. ${ }^{1}$ Ninety percent of malaria-related deaths occur in Africa, ${ }^{2}$ and in Uganda alone, although much reduced in recent years, Feachem et al estimated there were 41,648 deaths in 2009. ${ }^{3}$ Sixty-three percent of Uganda's 37.58 million people still live in areas of high transmission, making this one of the country's most important health issues. ${ }^{4}$ The commonest strain of malaria in Uganda is Plasmodium 
falciparum, making up $90 \%-98 \%$ of all infections, ${ }^{4}$ and the problem is compounded by Uganda's high HIV prevalence: $7.2 \%$ of adults aged $15-49$ years. ${ }^{5}$ Co-infection with HIV increases the severity of malaria, particularly in pregnant women and their neonates. Children under 5 years old, pregnant women, and HIV patients are all particularly susceptible to malaria. ${ }^{6}$

The World Health Organization (WHO) ${ }^{7}$ and Uganda Clinical Guidelines $(2010)^{8}$ both recommend parasitological diagnosis before commencing antimalarial treatment, either by blood-smear microscopy, where laboratory facilities permit, or by rapid diagnostic test (RDT). According to the WHO and the Uganda Clinical Guidelines (2010), blood smears should be done in all patients fulfilling any of the following criteria: patients presenting with signs of severe malaria; patients who have taken treatment for 2 days, whose symptoms persist; all children under 4 months of age with signs of malaria; and all pregnant women with signs of malaria.

Severe malaria is defined as having asexual forms of $P$. falciparum in the blood plus any of an extensive list of the more dangerous signs of malaria, such as acidosis, respiratory distress, or convulsions. ${ }^{8}$

The prudent use of these diagnostic tests has seen a decline in the presumptuous diagnosis of any fever as malaria; more accurate diagnosis means more appropriate treatment distribution and therefore better disease control, faster individual recovery times, and reduced mortality. ${ }^{9}$ This improved targeting saves resource-poor nations valuable funds, both by reducing inappropriate medication use and by reducing hours lost by the workforce due to illness. ${ }^{10}$ Since 2007, malaria diagnosis has been offered for free in the Ugandan public sector, but in a country in which not only is malaria a considerable public health burden but also to many fever is synonymous with malaria, ${ }^{11}$ it is important to assess the quality of diagnostic practice.

The aim of the clinical audit reported here was therefore to ascertain the proportion of patients undergoing appropriate diagnostic testing for malaria in Kisiizi Hospital, Uganda, prior to receiving treatment, in accordance with guidelines.

\section{Methods}

\section{Design}

This was a clinical audit, comparing current practice against Ugandan Clinical Guidelines $(2010)^{8}$, which closely match those of the WHO, which state that all patients must undergo a diagnostic test prior to being commenced on antimalarial treatment, the nature of that test being dictated by several factors as described earlier.

The standard used was therefore that $100 \%$ of patients receiving such treatment must also have undergone proper diagnostic testing.

\section{Setting and participants}

Kisiizi Hospital lies in Rukungiri District in southwestern Uganda. The area is mountainous and forested; the surrounding communities are mostly small, poor, rural villages supported by subsistence agriculture. While there are small government health centers in several villages, Kisiizi remains the largest and best-equipped health facility in the area. The hospital has over 200 beds divided between Medical, Surgical, Pediatric, Maternity, Isolation, and Psychiatry wards.

It is a private hospital affiliated with the Church of Uganda, receiving financial and material donations from overseas, largely from the UK and the Netherlands. The hospital also runs a successful health insurance scheme, which allows local participants to access much emergency health care without direct cost. As a result, while traditional treatments are still prevalent, local health-seeking behavior often incorporates the hospital. There is also a nursing college on site and staffing levels are generally high.

Importantly for this study, the hospital laboratory is capable of performing parasitological diagnostic tests for malaria.

\section{Data collection}

Data were collected over a continuous 10-day period in May 2014. Data collection involved visiting each ward daily at $5 \mathrm{pm}$ and enquiring if any new patients had commenced antimalarial treatment. If they had, their records were checked for evidence of diagnostic testing, as well as for any factors which would require them to have received laboratory bloodsmear microscopy diagnosis, rather than RDT. This was cross-checked with laboratory records to ensure accuracy and coverage. The pharmacy was asked to scan every prescription they filled for antimalarial drugs, so that no cases would be missed. Patients already known to be on antimalarial treatment would have their notes checked daily for the length of their admission, as patients who receive an RDT but who do not respond to treatment within 2 days should then undergo microscopic diagnosis. ${ }^{8}$ All patients receiving antimalarial medication were included.

To allow the inclusion of the Outpatient Department, where many malarial patients are seen, the history sheets attached to prescriptions were also scanned by the pharmacy. If the nature of the diagnostic test performed was unrecorded, 
the patient was looked up in the laboratory logbook, which held the information. If their name was also absent from the laboratory, it was assumed no diagnostic test was performed.

\section{Data analysis}

The proportion of the total patients who were correctly managed was calculated and then the figure was stratified by ward or department, sex, and age group. Statistical analysis was then performed to assess whether the differences between any of these groups were statistically significant. Fisher's exact test was used in place of the chi-square test as the values involved were often small.

As two patients did not have their ages recorded, calculations involving comparisons based on age groups did not include these two patients. This explains any inconsistency in percentages provided.

\section{Ethical statement}

This project involved a clinical audit using pre-existing data so ethical approval was not required. All data were treated with the strictest confidence throughout, and no patient identifiers were used at any point. This research complies with the guidelines of the Declaration of Helsinki.

\section{Results}

A total of 59 patients met the inclusion criteria for this audit. Patient demographic information is summarized in Table 1. Age was not recorded in the notes of two patients but data were otherwise complete. Of the 59, 35 (59.3\%) patients were male and Outpatients provided the greatest number of malaria patients: 25 (42.4\% of the total). It should be noted that only five patients were included, collectively, from Maternity (two), Surgical (two), and Psychiatry (one); these small figures make interpretation of the data and the

Table I Patient information

\begin{tabular}{ll}
\hline Characteristic & Data \\
\hline Median age, years (interquartile range) & $18(4.5-31.0)$ \\
Sex, $\mathrm{n}(\%)$ & \\
Male & $35(59.3)$ \\
Female & $24(40.7)$ \\
Ward/department, $\mathrm{n}(\%)$ & \\
Outpatient & $25(42.4)$ \\
Medical & $8(13.6)$ \\
Surgical & $2(3.4)$ \\
Pediatric & $16(27.1)$ \\
Maternity & $2(3.4)$ \\
Isolation & $5(8.5)$ \\
Psychiatry & $1(1.7)$ \\
\hline
\end{tabular}

conclusions drawn from them less significant, relative to the other units.

In total, 50 of the 59 patients $(84.7 \%)$ were appropriately diagnosed prior to treatment. Of the nine patients managed contrary to guidelines, four (6.8\% of patients) had no diagnostic test, two had a negative RDT but received treatment, two had both a negative RDT and negative blood smear but received treatment, and one had a positive blood smear but received no treatment.

As shown in Table 2, three wards (Surgical, Isolation, and Psychiatry) performed the correct diagnostic test in every patient. These eight patients, however, represent only $13.6 \%$ of the hospital's malaria cases during this period, a very small figure. The remaining departments achieved proportions ranging from $87.5 \%$ in Pediatrics to $50 \%$ in Maternity, the lowest figure, although again, this figure represents only two patients.

The youngest patient found with malaria was 9 months old and the oldest was 80 years old. There were 28 children under the age of 18 in this audit (49.1\% of the total). As shown in Table 3 , the proportion of this age group that was inappropriately managed was approximately half of the figure among those aged 18-30 and those over 30 years: $10.7 \%$ compared to $20 \%$ and $21.4 \%$, respectively.

Lastly, Table 4 demonstrates the difference between male and female patients. Men constituted almost $60 \%$ of all patients and were significantly more likely to be managed according to the guidelines: $94.3 \%$ compared to $70.8 \%$ of females $(P=0.0242)$.

Given the small number of patients who were inappropriately managed, data analysis using Fisher's exact test revealed that only the difference between correctly diagnosing males and females was statistically significant at the 5\% level. Between wards or departments, the largest difference in the percentage of correctly treated patients was between Maternity and Isolation $(1 / 2[50 \%]$ vs $5 / 5$ [100\%] patients

Table 2 Number and proportion (n [\%]) of patients correctly managed, stratified by ward or department

\begin{tabular}{llll}
\hline $\begin{array}{l}\text { Ward/ } \\
\text { department }\end{array}$ & $\begin{array}{l}\text { In accordance } \\
\text { with guidelines }\end{array}$ & $\begin{array}{l}\text { Not in accordance } \\
\text { with guidelines }\end{array}$ & Total \\
\hline Outpatient & 2 I (84.0) & $4(16.0)$ & $25(42.4)$ \\
Medical & $6(75.0)$ & $2(25.0)$ & $8(13.6)$ \\
Surgical & $2(100.0)$ & $0(0.0)$ & $2(3.4)$ \\
Pediatric & I4 (87.5) & $2(12.5)$ & $16(27.1)$ \\
Maternity & I $(50.0)$ & $\mathrm{I}(50.0)$ & $2(3.4)$ \\
Isolation & $5(100.0)$ & $0(0.0)$ & $5(8.5)$ \\
Psychiatry & $\mathrm{I}(100.0)$ & $0(0.0)$ & $\mathrm{I}(1.7)$ \\
Total & $50(84.7)$ & $9(15.3)$ & $59(100.0)$ \\
\hline
\end{tabular}


Table 3 Number and proportion (n [\%]) of patients correctly managed, stratified by age

\begin{tabular}{llll}
\hline $\begin{array}{l}\text { Age group, } \\
\text { years }\end{array}$ & $\begin{array}{l}\text { In accordance } \\
\text { with guidelines }\end{array}$ & $\begin{array}{l}\text { Not in accordance } \\
\text { with guidelines }\end{array}$ & Total \\
\hline$<18$ & $25(89.3)$ & $3(10.7)$ & $28(49.1)$ \\
$18-30$ & $12(80)$ & $3(20)$ & $15(26.3)$ \\
$>30$ & $11(78.6)$ & $3(21.4)$ & $14(24.6)$ \\
Total & $48(84.2)$ & $9(15.8)$ & $57(100.0)$ \\
\hline
\end{tabular}

treated correctly, $P=0.2857$ ) and among age groups, the greatest difference in the number of correctly treated patients was between those aged under 18 and those aged over 30 years (25/28 [89.3\%] vs $11 / 14$ [78.6\%], $P=0.3825)$.

\section{Discussion}

These results show that Kisiizi Hospital is achieving relatively high compliance with WHO guidelines and the Uganda Clinical Guidelines $(2010)^{7,8}$ with regards to the correct diagnostic testing of patients prior to commencing antimalarial treatment. While not every department is performing perfectly, the hospital as a whole is operating at a high standard.

It is worth noting that this area of Uganda, the Kigezi Highlands, lies at relatively high altitude and until recently malaria was uncommonly a problem, particularly in the dry season, when this audit was conducted. Anecdotally, locals note that the seasons have shifted to be later in the year. The rains have also been less reliable. Against this backdrop, malaria has slowly become more of a concern and these 59 cases are considered an unusually high number for May. The relationship between climate change and altered malarial epidemiology at altitude remains unclear ${ }^{12-15}$ but may contribute to these changes.

Elsewhere in Africa, adherence to WHO guidance has been much poorer. In a 2009 study in rural Ghana, only $10.2 \%$ of febrile children were formally tested for malaria; in one hospital, only four RDTs were performed in 6 months. Although being appropriately tested was associated with a lower chance of receiving treatment, 55.8\% of children who tested negative were still given antimalarial medication and $7.1 \%$ of parasite-positive children were treated with

Table 4 Number and proportion (n [\%]) of patients correctly managed, stratified by sex

\begin{tabular}{llll}
\hline Sex & $\begin{array}{l}\text { In accordance } \\
\text { with guidelines }\end{array}$ & $\begin{array}{l}\text { Not in accordance } \\
\text { with guidelines }\end{array}$ & Total \\
\hline Male & $33(94.3)$ & $2(5.7)$ & $35(59.3)$ \\
Female & $17(70.8)$ & $7(29.2)$ & $24(40.7)$ \\
Total & $50(84.7)$ & $9(15.3)$ & $59(100.0)$ \\
\hline
\end{tabular}

an antibiotic, which could have resulted in unnecessary morbidity. ${ }^{16}$

A 2012 Nigerian audit of the management of children with malaria under 5 years old found that only $28.5 \%$ of patients had any diagnostic test performed. ${ }^{17}$ Of these, just $18.9 \%$ had a RDT, showing underuse of what could be an important resource in combating malaria in developing countries.

Kisiizi's figure of $84.7 \%$ compliance across the hospital is considerably better than these examples. That some wards attained $100 \%$ correct procedure should be commended, despite the small numbers involved. It is particularly encouraging that the Isolation unit followed correct procedure in every instance as the patients on this ward often have several severe comorbidities, increasing the risk posed by malaria. ${ }^{18}$

The two largest departments by number of malarial patients were Outpatients and Pediatrics. This was anticipated as, firstly, almost every patient who is not referred from elsewhere is admitted through Outpatients and, secondly, malaria is often a more serious problem, requiring admission, in children. ${ }^{19}$ Interestingly, it is typically more severe in pregnant women as well, however this was not reflected in the caseload of this audit, perhaps due to expectant mothers not presenting. Both Outpatients and Pediatrics obtained promising results ( $84 \%$ and $87.5 \%$ correctly treated, respectively).

Given the greater risk in children, pregnant women, and those with significant comorbidities, it is particularly important that these audit figures are not just maintained but improved. If these cases can be managed entirely in line with evidence-based WHO guidelines, there is a possibility of reducing morbidity and mortality to a greater degree than in the general population. Correct management of these groups should be the primary concern of hospital antimalarial efforts. The necessity for this focus is augmented by the number of patients under 18 years almost equaling the number of adults, reflecting the population of Uganda as a whole. ${ }^{20}$

The gap in correct management between males and females gives cause for concern however, as it is both significant and unexpected. No explanation for this result is immediately obvious. It might be expected that the need for blood smears in pregnant women may be overlooked; however both pregnant patients had the correct test performed. It may otherwise relate to the health behaviors of either the patients with malaria or the staff treating them. Gender roles remain very traditional in Uganda and this has been shown to be a barrier to women accessing health care, not just in Uganda but across sub-Saharan Africa. ${ }^{21-23}$ Whatever the cause, this gender inequality should be tackled. It should be 
raised with staff to ensure awareness of the issue and correct case management. There are weekly medical staff meetings at which teaching is provided; this could be the subject of one such tutorial.

Promisingly, blood smears were generally performed over a RDT when required by guidance. Throughout the audit, there were no patients below 4 months of age and of the very few pregnant women, all had blood-smear microscopy, although one positive result was ignored and treatment withheld. All patients with symptoms persisting for more than 2 days despite treatment had already had a blood smear conducted, although often this was repeated for reassurance. With regard to severe malaria, it becomes harder to assess the quality of case management. Several of the factors defining severe malaria are either difficult or currently impossible to test for at Kisiizi Hospital, such as the definitive presence of acute kidney injury or a hematocrit level. Monitoring and documentation were also frequently insufficient to highlight criteria for severe disease. Given the inability to reliably identify many severe malaria cases, it was decided not to include this as a variable in correct testing. Anecdotally, all of the few recognized cases were correctly diagnosed by blood-smear microscopy, either in addition to RDT or alone. Improving monitoring, record keeping, and access to investigations would allow more satisfactory identification of severe malaria and permit proper audit of its diagnostic testing. Alternatively, universal use of blood-smear microscopy would eliminate doubt in this area; however this negates the purpose of RDT in saving human, financial, and laboratory resources.

\section{Strengths and limitations}

Efforts were made to conduct this research at a consistently high standard; however, some limitations are recognized. Firstly, identifying patients for inclusion relied upon ward staff knowing their patients and the quality of handwritten notes. Often, patients would be identified by staff as receiving antimalarial therapy but the notes made no mention of it, or vice versa if the patient was new to the ward. The record of the diagnostic test was often difficult to find, particularly as requests are handwritten and may have been in the laboratory when the notes were being examined. The inconsistent quality of note keeping and routine observations also meant that signs indicating severe malaria were infrequently recorded, necessitating the exclusion of severe malaria as an audit variable. It is likely, however, that proper recognition of all severe disease would result in only a small increase in incorrect management as patients who are noticeably unwell and who return a negative RDT usually receive a confirmatory blood-smear test.
In some departments, patients' diagnosis and antimalarial treatment were only recorded in the laboratory or pharmacy, making identification difficult. This was a particular problem in Outpatients, as no master record is kept of the patients seen, their presenting complaints, or the consultation outcome. While disagreement between pharmacy prescriptions and laboratory records of patients' diagnostic tests was rare, and therefore ensured as many eligible patients as possible were captured by the audit, it is feasible that an unknown number of patients were not included. It also had to be assumed that any patient filling an antimalarial prescription whose notes had no record of a diagnostic test, and who had no laboratory test record, was incorrectly managed. Again, despite reasonable effort, it was impossible to know if such patients truly had no diagnostic test.

Furthermore, as the audit continued, doctors and clinical officers became more aware of its aims and reported that they were being more careful to follow guidelines. While this is beneficial for patient health, it means the data collected may not be entirely representative of true hospital practice. Conversely, it was noted anecdotally that a small number of clinicians represented the majority of incorrect diagnostic procedures. When approached informally, these members of staff stated that prescribing antimalarial therapy in patients who were, in their opinion, obviously suffering from the disease, was a matter of routine. They viewed diagnostic tests as an unnecessary formality. While understandable in this setting, this attitude could be harmful, given the body of evidence which stands behind the correct case-management guidelines. Again, staff education would probably be sufficient in this instance, or else making the process of ordering the tests simpler, facilitating their correct use.

\section{Conclusion}

This audit found that Kisiizi Hospital performs relatively well in correct diagnostic testing prior to treating malaria. Despite staff awareness potentially skewing these results and variable record keeping potentially affecting data quality, this audit achieved its stated aims.

Disparities between departments and age groups were not statistically significant; however, the difference in appropriate management between men and women was significant and requires investigation and improvement. This might be adequately addressed through staff education, particularly regarding pregnant women, given their higher risk. Similarly, better monitoring, note keeping and recording of patient observations, biochemistry, hematology, and other biological 
markers is required to ensure that cases of severe malaria are identified.

While these results are very promising, especially given the compliance of health care facilities in comparable settings, there is room for improvement and future work in this area could include a re-audit of these criteria, an audit of antimalarial treatment administration, ${ }^{8}$ or a comparison of this hospital's performance against other local, national, or regional health care institutions to assess the generalizability of these results. A knowledge, attitude, and practice study examining the beliefs of medical staff regarding malarial management and the impact this has on staff practice would also be enlightening and might provide further avenues to improve service delivery.

\section{Acknowledgments}

The authors would like to acknowledge Dr I Spillman, medical superintendent of Kisiizi Hospital, for granting permission for this audit to be conducted and for his logistical support. The authors also wish to acknowledge the support of the Kisiizi medical, nursing, laboratory, and pharmacy staff for facilitating data collection in the field.

\section{Disclosure}

The authors declare no conflicts of interest in this work.

\section{References}

1. Rietveld A, Kurdova-Mintcheva R; Roll Back Malaria Partnership. Eliminating Malaria: Learning from the Past, Looking Ahead. Roll Back Malaria Progress and Impact Series Number 8. Geneva: World Health Organization (WHO); 2011. Available from: http://archiverbm. rollbackmalaria.org/ProgressImpactSeries/docs/report9-en.pdf. Accessed May 4, 2015.

2. Grayson M. Malaria. Nature. 2012;484(7395):S13.

3. Feachem RG, Phillips AA, Hwang J, et al. Shrinking the malaria map: progress and prospects. Lancet. 2010;376(9752):1566-1578.

4. Ugandan Ministry of Health Malaria Control Programme. Uganda Malaria Control Strategic Plan 2005/6-2009/10. Kampala: Ugandan Ministry of Health; nd. Available from: http://www.eac.int/health/index. php?option=com_docman\&task=doc_download\&gid=52\&Itemid=180. Accessed May 4, 2015.

5. Joint United Nations Programme on HIV and AIDS (UNAIDS). Uganda [web page on the Internet]. Geneva: UNAIDS; nd. Available from: http://www.unaids.org/en/regionscountries/countries/uganda/. Accessed January 12, 2014.

Clinical Audit

\section{Publish your work in this journal}

Clinical Audit is an international, peer-reviewed, open access journal focusing on the processes and outcomes of clinical audit in any area of healthcare. All aspects of patient care are addressed within the journal and practitioners from all disciplines are invited to submit their work. Areas covered include: Publication of audits; How an audit has changed practice; Submit your manuscript here: http://www.dovepress.com/clinical-audit-journal
6. Shetty P. The numbers game. Nature. 2012;484(7395):S14-S15.

7. WHO Global Malaria Programme. World Malaria Report 2013. Geneva: WHO; 2013. Available from: http://www.who.int/iris/bitstream/10665/ 97008/1/9789241564694_eng.pdf. Accessed May 4, 2015.

8. Ugandan Ministry of Health. Uganda Clinical Guidelines 2010: National Guidelines on Management of Common Conditions. Kampala: Ugandan Ministry of Health; 2010. Available from: http://www.health. go.ug/docs/ucg_2010.pdf. Accessed May 4, 2015.

9. Reyburn H. New WHO guidelines for the treatment of malaria. $B M J$. 2010;340:c2637.

10. Feachem RG, Phillips AA, Targett GA, Snow RW. Call to action: priorities for malaria elimination. Lancet. 2010;376(9752):1517-1521.

11. Chandler CI, Hall-Clifford R, Asaph T, Pascal M, Clarke S, Mbonye AK. Introducing malaria rapid diagnostic tests at registered drug shops in Uganda: limitations of diagnostic testing in the reality of diagnosis. Soc Sci Med. 2011;7(6):937-944.

12. Caminade C, Kovats S, Rocklov J, et al. Impact of climate change on global malaria distribution. Proc Natl Acad Sci U S A. 2014;111(9): 3286-3291.

13. Parham PE, Michael E. Modelling climate change and malaria transmission. Adv Exp Med Biol. 2010;673:184-199.

14. Reiter P. Global-warming and vector-borne disease in temperate regions and at high altitude. Lancet. 1998;351(9105):839-840.

15. Himeidan YE, Kweka EJ. Malaria in East African highlands during the past 30 years: impact of environmental changes. Front Physiol. 2012;3:315.

16. Webster J, Baiden F, Bawah J, et al. Management of febrile children under five years in hospitals and health centres of rural Ghana. Malar J. 2014; 13:261.

17. Udoh E, Oyo-Ita A, Odey F, et al. Management of uncomplicated malaria in underfives in private and public health facilities in Southeastern Nigeria: a clinical audit of current practices. Malar Res Treat. 2013;2013:575080.

18. Hartopo AB, Wijisaksono DP. A lethal case of Plasmodium falciparum infection in a young patient with end-stage renal failure who underwent regular hemodialysis. Intern Med. 2010;49(17):1867-1870.

19. Eddleston M, Davidson R, Brent A, Wilkinson R. Oxford Handbook of Tropical Medicine. 3rd ed. Oxford, New York, NY: Oxford University Press; 2012.

20. United Nations Department of Economic and Social Affairs Population Division Population Estimates and Projections Section. World Population Prospects: The 2012 Revision. Vol 1, Comprehensive tables. ST/ESA/SER.A/336. New York, NY: United Nations; 2013.

21. Ssali SN. Revisiting choice: gender, culture and privatised health care in Uganda. Agenda. 2006;20(68):42-53.

22. Okong P. HIV/AIDS and women's health in Uganda: lingering gender inequity. J Obstet Gynaecol Can. 2006;28(11):980-982.

23. Adjiwanou V, LeGrand T. Gender inequality and the use of maternal healthcare services in rural sub-Saharan Africa. Health Place. 2014;29: $67-78$.

Practical tips on how to do audits and to avoid pitfalls; How audits have changed patient care; Calls and justifications for new audits. The manuscript management system is completely online and includes a very quick and fair peer-review system, which is all easy to use. Visit http://www.dovepress. com/testimonials.php to read real quotes from published authors. 